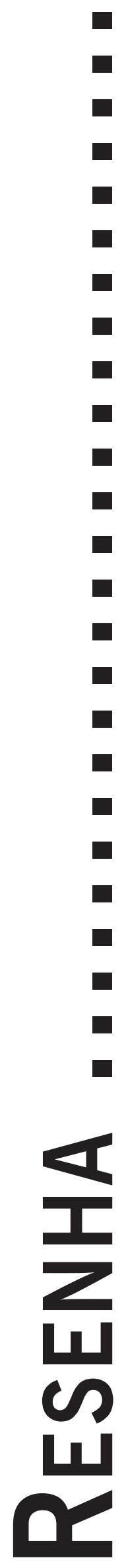




\title{
UMA LEITURA ACERCA DA IMAGINAÇÃO EM SARTRE
}

\author{
Jean-Paul Sartre, “A Imaginação”, Porto Alegre: L\&PM (2013)
}

Edelu Kawahala

RODRIGo Diaz De ViVAR y SOlER

Publicado por Sartre originalmente em 1936 A Imaginação (Sartre, 1936/2013) prefigura ao lado de outros ensaios como A Transcendência do Ego (Sartre, 1937/2014), Esboço Para Uma Teoria das Emoções (Sartre, 1939/2006) e O Imaginário (Sartre, 1940/1987) no sentido de ilustra as reflexões preliminares do que viria a ser seu grande tratado ontológico, no caso O Ser e o Nada (Sartre, 1945/2005). Neles podemos encontrar, portanto, o projeto longitudinal de Sartre no que corresponde à exploração das condições de possibilidade para a ilustração de um método fenomenológico no campo da psicologia.

Logo no início do livro A Imaginação (Sartre, 2013) trata de deixar claro que seu objetivo consiste em elaborar uma leitura sobre o conceito de consciência à luz da fenomenologia. É preciso deixar claro que a consciência a qual Sartre se refere está inscrita no projeto existencialista de sua ontologia fenomenológica, no sentido compreendê-la não como um mero efeito cognitivo, mas sim como algo relacionado à intencionalidade já que ela se apresenta como movimento pré-reflexivo anterior ao próprio pensar. Nesse sentido, pode-se destacar que a intenção de Sartre em A Imaginação consiste em explicitar a dimensão ontológica na qual o Ser é aquele que possui consciência da sua existência.

De modo nenhum minha consciência poderia ser uma coisa, porque seu modo de ser em si é precisamente um ser para si. Existir, para ela, é ter consciência da sua existência. Ela aparece como uma pura espontaneidade diante do mundo das coisas é pura inércia. Podemos, portanto, afirmar desde a origem dois tipos de existência: de fato, é na medida em que são inertes que as coisas escapam à dominação da consciência; é sua inércia que salvaguarda e que conserva sua autonomia. (Sartre, 2013, p. 7)

Essas palavras indicam o próprio deslocamento do conceito de consciência empreendido por Sartre desdobrado na perspectiva da suspensão do juízo fenomenológico que o leva a compreender a discriminação entre a existência como uma coisa e a existência como uma imagem. E é justamente esse problema que leva Sartre a dedicar-se a pensar a imaginação como condição fenomenológica proveniente da experiência do vivido. Deste modo, para Sartre a imaginação não é meramente um processo mental, mas sim o desdobramento de uma apreensão entre o agir de nossa consciência no mundo e a maneira pela qual elaboramos nossas experiências daquilo que nos é oferecido. Entretanto, para que tal premissa seja de fato explicitada resta explorar os contornos de uma crítica em relação ao que Sartre chama de antropologia do psicologismo.

Resta, portanto, empreender uma leitura acerca de uma possível história da imaginação no contexto das ideias psicológicas. Sartre parte do pressuposto de que se quisermos elaborar uma analítica da imaginação deve-se recorrer a um olhar sobre os grandes sistemas metafísicos que culminaram com a criação da psicologia moderna numa espécie de experiência apriori da imagem sem levar em conta o problema ontológico radical no qual ela está associada.

Deter-se sobre essa história implica elaborar um processo de revisão sobre os sentidos atribuídos a imaginação pela psicologia moderna e seus critérios metodológicos provenientes do positivismo. Para Sartre, a psicologia do século XIX que advogava para si o estatuto científico semelhante aos das ciências naturais ainda, encontrava-se embaraçada por velhas questões presentes nos grandes sistemas metafísicos desde Descartes. Essas ressonâncias estariam inscritas no paradigma positivista da ciência psicológica do século XIX, pois ele foi o primeiro filósofo a separar as sensações corporais do que aquilo que faz parte da consciência. Descartes (2005) costumava afirmar que matéria e consciência se excluem e, neste caso, a imagem seria meramente uma representação dos objetos exteriores. Tem-se neste caso a criação por parte do sujeito de um mundo interior alheio às manifestações exteriores. Deste modo, a imagem seria aquilo que possui uma impressão material produzida no cérebro do indivíduo.

Sartre irá argumentar que a psicologia moderna necessitaria passar por uma nova proposta metodológica 
caso ela quisesse se emancipar do que ele mesmo chama de mundo das essências. Na realidade, Sartre defende a emergência de uma práxis psicológica absolutamente contrária às teorias da intuição existentes até o aparecimento da fenomenologia. Em outras palavras, não se trata somente de perceber o sujeito como ser-no-mundo, mas compreender que este sujeito é um ser que representa o mundo e a si mesmo.

Vemos aqui o germe do neorrealismo americano. Mas todas essas afirmações metodológicas, ontológicas e psicológicas decorrem analiticamente do abandono das essências cartesianas. A imagem não se transformou em nada, não sofreu nenhuma modificação enquanto o céu inteligível desmoronava, pela simples razão que ela já era, em Descartes, uma coisa. É o advento do psicologismo, o qual, sob diversas formas, não é senão uma antropologia positiva, isto é, uma ciência que quer tratar o homem como um ser no mundo, negligenciando o fato essencial de que o homem é também um ser que se representa o mundo e a si mesmo no mundo. (Sartre, 2013, p. 21)

Como se sabe a imagem é um problema caro à psicologia. Disso decorre o fato de que sem a definição de um percurso metodológico adequado ela não consegue ultrapassar o campo da intuição segundo Sartre caracterizando-se como uma mera metafísica frustrada. De acordo com Sartre mesmo os psicólogos ligados à corrente do neokantismo não foram capazes de pensar o papel da imagem a partir de uma experiência do vivido justamente porque negligenciaram um único aspecto: o papel político da experiência do pensamento como desdobramento da imaginação. Esse parece ser o posicionamento político adotado por Sartre nas entrelinhas de seu livro. Ou seja, não se trata mais de afirmar à imaginação de um eu autônomo, mas uma espécie de imagem que está diretamente associada à vida social e aqui emerge não a separação entre sujeito e objeto, e sim a verdadeira síntese cujo maior expoente é a fenomenologia, pois de acordo com esse saber enquanto que a imaginação remete a consciência imaginante o pensar está ligado a profusão da experiência reflexiva, logo a consciência existe desdobrada no mundo em ato, pois toda consciência é consciência de alguma coisa.

Isso significa que para Sartre, a consciência é muito mais do que um mero processo reflexivo. Na realidade, ela seria uma conjetura da ação já que ela não pertence a um indivíduo, nem é a matéria prima pela qual separamos o mundo interior do exterior, mas simplesmente está dada no mundo. Da mesma forma que a percepção não pode ser confundida como representação, mas sim como um devir maquínico da experiência já que a imaginação é para Sartre movimento, uma imagem que não reside em parte alguma.

Quando se trata de imaginação deve-se desconstruir a tese de que ela é uma coisa diante do pensamento. Em
Investigações Lógicas podemos constatar a crítica mais corrosiva de Husserl ao psicologismo. Do conteúdo positivista que concebe a consciência como fenômeno cognitivo, Husserl percebe a existência de significações representadas que se deixam constituir por conteúdos.

Deste modo, percebe-se que a investigação de Sartre neste pequeno, porém emblemático ensaio reserva um olhar sobre a história da imagem no pensamento ocidental desde Descartes até a psicologia do século XIX a partir da formulação do seguinte questionamento: em que momento a imagem passa a ser uma categoria sujeitada à experiência reflexiva? Ou perguntado de outro modo: quando a imagem se tornou um desdobramento da racionalidade? Enveredando-se pelos contornos da fenomenologia Sartre parte do pressuposto de que a imagem reflete o fenômeno da consciência percebida como intencionalidade não estando, de modo algum, fora do mundo e fora da realidade. Isso por conta de um único aspecto; nossa percepção é sempre superior à razão. Por conta disso é que uma psicologia da imaginação deve levar em conta o papel fenomenológico dos sentidos e não sua pura especulação. Isso quer dizer que para se pensar as bases de uma psicologia concreta deve-se levar em conta que a imaginação é sempre da ordem do vivido, embora deva-se ressaltar que esse vivido não esteja inscrito na categoria do pensamento, já que suas características envolvem os contornos daquilo que é pré-reflexivo. Justamente por conta desse aspecto é que não se pode confundir consciência com racionalidade, pois a consciência se encontra no plano fenomenológico e como tal deve ser compreendida como uma condição ontológica.

É diante dessa constatação que Sartre irá considerar que o grande acontecimento que impulsionou a fenomenologia foi à publicação, por parte Husserl de A Crise das Ciências Europeias e a Fenomenologia Transcendental (Husserl, 2012), pois é nesse escrito que será problematizado definitivamente todas as essências das atitudes naturais. A fenomenologia apresentada nesse contexto seria um método para uma nova possibilidade do fazer psicológico desprovido de qualquer espontaneidade ou gratuidade, já que ela procura pensar a consciência, não como intuição, mas como ato e nesse sentido, a leitura empregada pela fenomenologia nada tem a ver com a construção de uma lógica cognitiva, mas com a própria apreensão da experiência do pensamento.

Indo na contramão da perspectiva positivista que tenta a todo custo prescrever uma racionalização do sujeito através da quantificação de seus sentimentos e experiências através de dados empíricos, a fenomenologia procura trabalhar com os elementos da imaginação através do sentido dado a experiência, cujo objetivo final seria o de pensar as bases de uma psicologia voltada para as questões que envolvem a dimensão ontológica do sujeito buscando investigar os sentidos e os significados que habitam a realidade psíquica a partir da sua temporalidade e da sua história, pois para Sartre (2013, p. 28) “a única 
maneira de existir para uma consciência é ter consciência que ela existe".

\section{Referências}

Descartes, R. (2005). O Discurso do Método. Porto Alegre: L \& PM.

Husserl, E. (2012). A Crise das Ciências Européias e a Fenomenologia Transcendental. Rio de Janeiro: Forense Universitária.

Sartre, J.P. (1987). Lo Imaginário. Buenos Aires: Ibero Americana.

Sartre, J.P. (2005). O Ser e o Nada: ensaio de ontologia fenomenológica. Petrópolis: Vozes.

Sartre, J.P. (2006). Esboço Para Uma Teoria das Emoções. Porto Alegre: L \& PM.

Sartre, J.P. (2013). A Imaginação. Porto Alegre: L \& PM.

Sartre, J.P. (2014). A Transcendência do Ego. Petrópolis: Vozes.

Rodrigo Diaz de Vivar y Soler - Doutorando em Filosofia pela UNISINOS, Mestre em Psicologia pela Universidade Federal de Santa Catarina, é Professor do Centro Universitário Estácio de Sá/SC. E-mail: diazsoler@gmail.com

Edelu Kawahala - Doutora em Literatura pela Universidade Federal de Santa Catarina e Professora do Centro Universitário Estácio de Sá/SC. Endereço Institucional: Rua Mário Coelho Pires, 221, bl.a, apto. 1302. São José/SC. CEP: 88101290. E-mail: edeluk@gmail.com

Recebido em 16.12.2015 Primeira Decisão Editorial em 11.10.2016 Aceito em 12.10.2016 